\title{
LIMITS OF HIGH FREQUENCY PERCUTANEOUS TRANSTRACHEAL JET VENTILATION USING A FLUIDIC LOGIC CONTROLLED VENTILATOR
}

\author{
R. Brian Smith, Miroslay Klain and Maciej Babinski
}

\begin{abstract}
A study was undertaken on dogs to find the limit of carbon dioxide exchange with high frequency jet ventilation using a fluidic logic controlled oxygen jet ventilator. Fifteen dogs were ventilated through a transtracheal catheter at respiratory rates up to 600 per minute. The following were recorded; aortic, pulmonary artery, pulmonary arterial wedge, and central venous blood pressures; intratracheal pressure; electrocardiogram; inspiratory and expiratory time of the jet; arterial and central venous blood gases; intermittent cardiac output.

Normal gas exchange was found up to a respiratory rate of 400 per minute with low tidal volume and low intratracheal pressures. There were no adverse circulatory effects up to a rate of 400 per minute. At rates of 500 and 600 per minute, cardiac contractility was unaffected, but a decreased heart rate and increased peripheral resistance produced a fall in cardiac output. There was no interference with the resumption of spontaneous ventilation during weaning.

In a control series of five dogs, apnoeic oxygenation was used. The $\mathrm{Pa}_{\mathrm{CO}_{2}}$ was allowed to reach $15.96 \mathrm{kPa}$ (120 torr). High frequency jet ventilation was then started at a rate of 600 per minute and decreased in increments to 100 per minute. Arterial blood gases were continuously recorded through an intra-arterial catheter connected to a mass spectrometer. The $\mathbf{P a} \mathrm{CO}_{2}$ gradually declined to normal levels as the rate decreased.
\end{abstract}

Several recent Scandinavian papers ${ }^{1-4}$ describe studies on dogs and man using respiratory rates up to 100 per minute during artificial ventilation. An insufflation catheter was introduced into a standard tracheal tube and good gas exchange was obtained with a small tidal volume. Airway pressure was low and there was little effect on the circulation compared with conventional respiratory rates of 12-20 per minute. With a special connector, the exhalation valve could be adjusted to obtain a positive end expiratory pressure (PEEP) effect.

While studying heart performance in dogs, Lunkenheimer, et al. ${ }^{5}$ observed that transtracheal pressure oscillations improved gas exchange. An electromagnetic vibrator was attached to a tracheal tube and adequate carbon dioxide elimination was found at frequencies between 23 and $40 \mathrm{~Hz}$ (1380-2400 per minute). Recently Butler, et al. ${ }^{6}$ described ventilation of four physician volunteers and three patients using oscillations of $15 \mathrm{~Hz}$ ( 900 per minute).

R. Brian Smith, M.D., Professor and Chairman. Macicj Babinski, M.D., Associate Professor, Department of Anesthesiology, The University of Texas Health Science Center, 7703 Floyd Curl Drive, San Antonio, TX 78284. Miroslav Klain, M.D., Ph.D., Associate Professor, University of Pittsburg.

Please address correspondence to: $R$. Brian Smith, M.D., Professor and Chairman, Department of Anesthesiology, The University of Texas Health Science Center, 7703 Floyd Curl Drive, San Antonio, TX 78284.
Respirators generally used in clinical practice are not capable of operating at high respiratory rates. In our previous work with transtracheal ventilation, ${ }^{7-10}$ we designed a fluidic logic controlled oxygen jet ventilator for this technique. " This ventilator has no moving parts and is capable of operating at respiratory rates up to 800 per minute. Our experimental results using ventilating rates up to 200 per minute in dogs with this ventilator, ${ }^{12}$ as well as clinical results during short laryngeal procedures, ${ }^{13}$ and in patients with respiratory failure ${ }^{14}$ have recently been reported. The results of these studies indicate that, at respiratory rates of 100 to 200 per minute, the limit of $\mathrm{Pa}_{\mathrm{CO}_{2}}$ exchange was not reached and respiratory rates could be increased even further. Therefore, we decided to study respiratory and circulatory changes at respiratory rates up to 600 per minute.

Because of the calculated low tidal volume using the ventilator at high rates, we speculated that turbulent airflow produced by the high frequency jets allows for adequate simultaneous movement of gases in and out of the lungs.

\section{Methods AND Materials}

Mongrel dogs with an average weight of $18 \mathrm{~kg}$ were anaesthetized with intermittent thiopentone and paralyzed with pancuronium. A 14-gauge

Canad. Anaesth. Soc. J., vol. 27, no. 4, July 1980 
special Angiocath ${ }^{1}, 212 \mathrm{~mm}$ ( $3 \frac{1}{4}$ inches) in length with two side holes near the tip, was inserted into the trachea percutaneously between the first and second tracheal ring. It was connected to the fluidic jet ventilator described below and the animals were ventilated at rates between 100 and 600 per minute. The upper airway was left in the natural position without an oropharyngeal airway or tracheal tube.

Variables recorded continuously on an Electronics for Medicine polygraph were:

1. Lead II of the electrocardiogram,

2. Aortic pressure through a polyethylenc catheter introduced through the femoral artery,

3. Pulmonary artery pressure and pulmonary artery wedge pressure using a No. 7 French Swan-Ganz thermodilution catheter,

4. Central venous pressure (from the proximal opening of the Swan-Ganz catheter),

5. Intratracheal pressure using a polyethylene catheter with the tip $10 \mathrm{~cm}$ below the level of the jet catheter, and

6. The inspiratory and expiratory time of the jet by fluidic pneumo-electric switch attached to the insufftation line.

Additionally, arterial and central venous blood samples were drawn intermittently from the aorta and pulmonary artery for blood gas analysis using an Instrumentation Laboratory 813 blood gas analyzer; and cardiac output was determined intermittently by the thermodilution technique.

The experiments were divided into two series:

Series 1. Fifteen dogs were ventilated at $\mathrm{F}_{\mathrm{O}_{2}}=$ 1.0. The initial measurements, including cardiac output and blood gas determination, were made following a stabilizing period of $\mathbf{3 0}$ minutes, at a respiratory rate of 100 per minute. The respiratory rate was then increased in increments of 100 , up to 600 per minute, allowing a stabilizing period of 30 minutes between the measurements at each level.

Series 2. In a control series of five dogs, the same technique was employed except that, at the beginning of the experiment, apnoeic oxygenation was used with a continuous insufflation of oxygen through the catheter. The $\mathrm{Pa}_{\mathrm{CO}_{2}}$ was allowed to reach $15.96 \mathrm{kPa}$ (120 torr) and high frequency jet ventilation was then started at a rate of 600 and decreased in increments of 100 . The arterial blood gases were recorded continuously through an intra-arterial cathether connected to a mass spectrometer (Perkin-Elmer).

At the end of each experiment, the muscle relaxant was reversed by prostigmin and the ani-

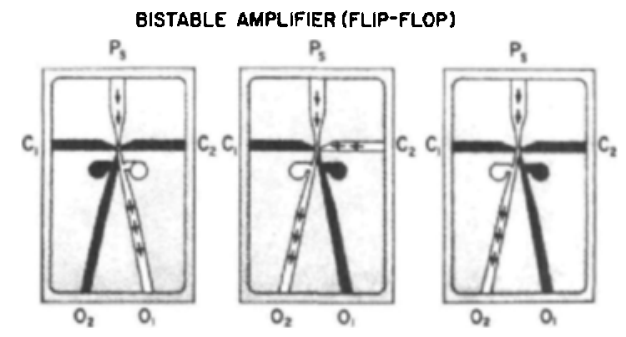

FIGURE 1 Bistable amplifier (Flip-flop). Ps, pressure source; $C_{1}, C_{2}$ control ports; $O_{1}, O_{2}$, output jets.

mals were maintained at a respiratory rate of 100 per minute until spontaneous breathing returned. The resumption of spontaneous ventilation was smooth in all experiments, with no bucking or coughing. When spontaneous ventilation was adequate, high frequency jet ventilation was discontinued and the jet cannula was removed.

\section{Description of ventilator}

The ventilator was designed for delivering oxygen under high pressure ( $50 \mathrm{psi}$ ) and is controlled by fluid amplifiers. The amplifiers operate at $3 \mathrm{psi}$ and the rate and inspiratory time can be adjusted. The principle of the bistable amplifier is shown in Figure 1. In the center, a signal at the $\mathrm{C}_{2}$ control port moves the oxygen stream from $\mathrm{O}_{1}$ to $\mathrm{O}_{2}$. When the signal is removed, the oxygen stream remains at $\mathrm{O}_{2}$. The main amplifier, seen in Figure 2, operates on this principle.

Figure 2 shows the arrangement of the fluid amplifiers in the ventilator. The main amplifier is in the center. Closing the regulator (2) progressively delays the feedback signal for the $O_{1}$ input going to the $\mathrm{C}_{4}$ control port of the amplifier. The signal from the control port switches the jet from

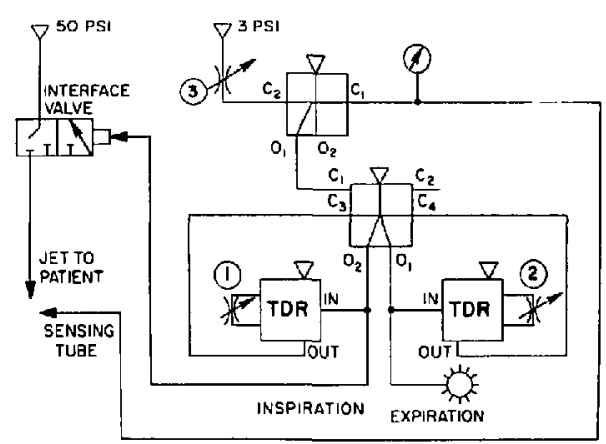

FIGURE 2 Schematic of ventilator fluid amplifiers. $\mathrm{C}_{1}-\mathrm{C}_{5}$, control ports; $\mathrm{O}_{1}, \mathrm{O}_{2}$, output jets; TDR, time delay relay. 
TABLE I

Blood Gas Results (Mean \pm S.E.) During High Frequency Ventilation

\begin{tabular}{|c|c|c|c|c|c|c|}
\hline \multirow{2}{*}{$\begin{array}{l}\text { Respiratory } \\
\text { rate }\end{array}$} & \multicolumn{2}{|c|}{$\mathrm{Pa}_{\mathrm{O}_{2}}$} & \multicolumn{2}{|c|}{$\mathrm{Pa}_{\mathrm{CO}_{2}}$} & \multirow{2}{*}{$\begin{array}{c}\mathrm{cH}^{+} \\
\mathrm{n} \mathrm{mol} / \mathrm{l}\end{array}$} & \multirow[b]{2}{*}{$(\mathrm{pH})$} \\
\hline & $\mathrm{kPa}$ & (Torr) & $\mathrm{kPa}$ & (Torr) & & \\
\hline 100 & $62.51 \pm 1.06$ & $(470 \pm 8)$ & $2.11 \pm 0.13$ & $(15.9 \pm 1.0)$ & $27.52 \pm 1.25$ & $(7.56 \pm 0.02)$ \\
\hline 200 & $64.51 \pm 0.93$ & $(485 \pm 7)$ & $2.90 \pm 0.19$ & $(21.8 \pm 1.4)$ & $34.67 \pm 1.63$ & $(7.46 \pm 0.02)$ \\
\hline 300 & $63.84 \pm 1.46$ & $(480 \pm 11)$ & $3.76 \pm 0.27$ & $(28.3 \pm 2.0)$ & $40.74 \pm 2.38$ & $(7.39 \pm 0.02)$ \\
\hline 400 & $61.85 \pm 1.46$ & $(465 \pm 11)$ & $5.04 \pm 0.55$ & $(37.9 \pm 4.1)$ & $48.98 \pm 3.36$ & $(7.31 \pm 0.03)$ \\
\hline 500 & $61.58 \pm 1.60$ & $(463 \pm 12)$ & $6.32 \pm 0.78$ & $(47.5 \pm 5.9)$ & $57.54 \pm 5.31$ & $(7.24 \pm 0.04)$ \\
\hline 600 & $59.85 \pm 1.46$ & $(450 \pm 11)$ & $7.39 \pm 0.98$ & $(55.6 \pm 7.4)$ & $64.57 \pm 5.95$ & $(7.19 \pm 0.04)$ \\
\hline
\end{tabular}

$\mathrm{PaO}_{2}$ - arterial oxygen tension; $\mathrm{Pa}_{\mathrm{CO}_{2}}$ - arterial carbon dioxide tension.

$\mathrm{O}_{1}$ to $\mathrm{O}_{2}$ and the other time delay relay with its regulator (1) comes into effect controlling the duration of the jet in the $\mathrm{O}_{2}$ output. Thus $\mathrm{O}_{1}$ represents expiration and $\mathrm{O}_{2}$ inspiration by operating an intermittent high pressure jet at the interface valve. The top amplifier and regulator (3) are part of a pressure sensing ventilator cut-off arrangement not used in this experiment.

\section{Statistical analysis}

Statistical analyses were made using the Student " $t$ " test. Level of significance was set at $p<$ 0.025 . Results at each respiratory rate were compared only with the value at the rate of 100 .

\section{Formulae used for calculations}

Total peripheral resistance (TPR)

$$
\mathrm{TPR}=(\overline{\mathrm{BP}}-\overline{\mathrm{CVP}}) 79.9 / \mathrm{CI}
$$

Pulmonary vascular resistance (PVR)

$$
\mathbf{P V R}=(\overline{\mathbf{P A}}-\overline{\mathbf{P A}} w) 79.9 / \mathrm{CI}
$$

\section{Results}

Blood Gases (Table I and Figure 3). At respiratory rates from 100 to 600 per minute, the $\mathrm{Pa}_{\mathrm{O}_{2}}$ remained between 59.85 and $64.51 \mathrm{kPa}(450$ and 485 torr) and the changes were not statistically significant.

The mean value of $\mathrm{Pa}_{\mathrm{CO}_{2}}$ showed a direct relationship between the respiratory rate and $\mathrm{Pa}_{\mathrm{CO}_{2}}$. At respiratory rates of 100,200 , and 300 per minute, the $\mathrm{Pa}_{\mathrm{CO}_{2}}$ was below normal, indicating severe hyperventilation at 100 and carbon dioxide rising as the rate increased (Table I). At 400 per minute, the $\mathrm{Pa}_{\mathrm{CO}_{2}}$ was normal; and at 500 and 600 per minute it was elevated to 6.38 and $7.45 \mathrm{kPa}$ (48 and 56 torr) respectively. $\mathrm{Pa}_{\mathrm{CO}_{2}}$ values at 400,500 , and 600 are statistically significantly
High Frequency Jet Ventilation

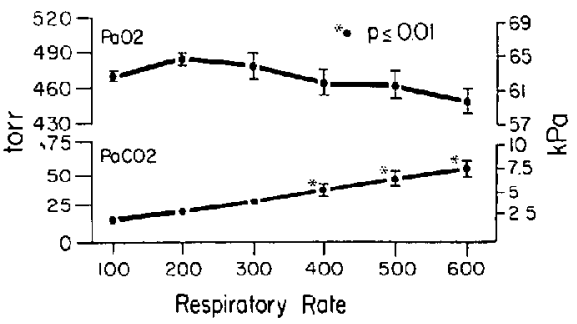

FIgure 3 Arterial blood gas results during high frequency jet ventilation.

increased from the starting values at 100 per minute.

The $\mathrm{pH}$ of arterial blood was directly proportional to the changes in $\mathrm{Pa}_{\mathrm{CO}_{2}}$, showing respiratory alkalosis or acidosis. Corresponding changes occurred in calculated standard bicarbonate.

Airway Pressures (Figure 4). Peak inspiratory pressure during high frequency ventilation was between 0.4 and $0.93 \mathrm{kPa}$ ( 3 and 7 torr). The differences were not statistically significant between different rates, even when it showed a tendency to decrease at higher rates.

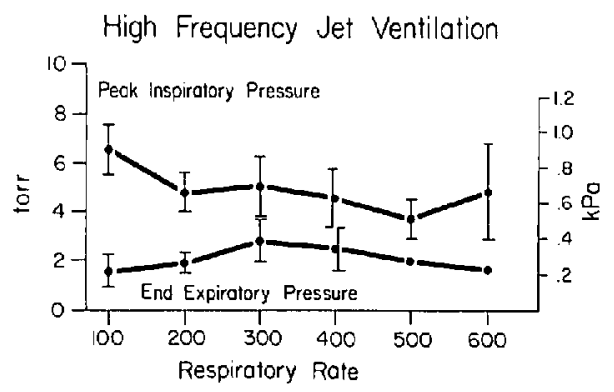

FIGURE 4 Intratracheal pressures during high frequency jet ventilation. 
TABLE II

Circulatory Pressures (Mean \pm S.e.) During High Frequency Ventilation (All in torr)

\begin{tabular}{ccccccc}
\hline \hline $\begin{array}{c}\text { Respiratory } \\
\text { rate }\end{array}$ & BP & BPs & CVP & PA & PAs & PAw \\
\hline 100 & $119 \pm 3$ & $161 \pm 5$ & $7 \pm 1$ & $16 \pm 1$ & $27 \pm 2$ & $10 \pm 1$ \\
200 & $116 \pm 2$ & $156 \pm 5$ & $8 \pm 1$ & $17 \pm 1$ & $28 \pm 2$ & $10 \pm 1$ \\
300 & $119 \pm 4$ & $158 \pm 6$ & $7 \pm 1$ & $17 \pm 1$ & $26 \pm 2$ & $9 \pm 1$ \\
400 & $127 \pm 7$ & $168 \pm 9$ & $7 \pm 1$ & $17 \pm 1$ & $27 \pm 2$ & $9 \pm 1$ \\
500 & $134 \pm 9$ & $178 \pm 13$ & $7 \pm 1$ & $18 \pm 1$ & $28 \pm 2$ & $9 \pm 1$ \\
600 & $124 \pm 5$ & $164 \pm 8$ & $8 \pm 1$ & $16 \pm 1$ & $26 \pm 2$ & $9 \pm 1$ \\
\hline
\end{tabular}

$\mathrm{BP}=$ mean arterial pressure, $\mathrm{BPs}=$ peak systolic arterial blood pressure, $\mathrm{CVP}=$ central venous pressure, $\mathrm{PA}=$ mean pulmonary artery pressure, $\mathrm{PAs}=$ peak systolic pulmonary artery pressure, $\mathrm{PAw}=$ pulmonary artery wedge pressure.

TABLE III

Cardiac Performance Parameters (Mean \pm S.E.) During High Frequency Ventilation

\begin{tabular}{cccccc}
\hline $\begin{array}{c}\text { Respiratory } \\
\text { rate }\end{array}$ & HR & CI & SI & TPR & PVR \\
\hline 100 & $211 \pm 17$ & $5.25 \pm 0.37$ & $26.2 \pm 2.4$ & $1759 \pm 114$ & $96 \pm 9$ \\
200 & $205 \pm 14$ & $4.95 \pm 0.33$ & $25.1 \pm 2.2$ & $1791 \pm 103$ & $115 \pm 8$ \\
300 & $191 \pm 14$ & $4.60 \pm 0.25$ & $25.4 \pm 2.3$ & $1987 \pm 104$ & $147 \pm 22$ \\
400 & $175 \pm 14$ & $4.97 \pm 0.32$ & $30.3 \pm 3.3$ & $1965 \pm 111$ & $121 \pm 16$ \\
500 & $152 \pm 16$ & $4.51 \pm 0.28$ & $32.3 \pm 3.5$ & $2260 \pm 96$ & $152 \pm 14$ \\
600 & $134 \pm 15$ & $4.02 \pm 0.29$ & $32.3 \pm 3.4$ & $2418 \pm 186$ & $159 \pm 17$ \\
\hline
\end{tabular}

$\mathrm{HR}=$ heart rate, $\mathrm{CI}=$ cardiac index $\left(\mathrm{L} \cdot \mathrm{min}^{-1} \cdot \mathrm{M}^{-2}\right), \mathrm{SI}=$ stroke index $\left(\mathrm{ml} / \mathrm{M}^{-2}\right), \mathrm{TPR}=$ total peripheral resistance (Dyne.sec.cm ${ }^{-5} \cdot \mathrm{M}^{-2}$ ), PVR $=$ pulmonary vascular resistance (Dyne. sec.cm $\left.{ }^{-5} \cdot \mathbf{M}^{-2}\right)$.

End-expiratory pressure was between 0.21 and $0.37 \mathrm{kPa}$ ( 1.6 and 2.8 torr). The differences were not statistically significant.

Circulatory Pressures (Table II). No significant changes were found in the following circulatory pressures throughout the experiment: systolic arterial, mean arterial, central venous, systolic pulmonary artery, mean pulmonary artery, and pulmonary artery wedge.

Cardiac Performance (Table III and Figure 5). Cardiac index did not change significantly up to the rate of 500 per minute but showed a significant decrease at the rate of 600 per minute. The small increase of stroke index with increasing rate was not statistically significant. With no change in stroke index, the change in cardiac index can be attributed only to the changes in the heart rate, which decreased with the increasing respiratory rate, showing significant decreases at rates of 500 and 600 per minute. The corresponding changes showing significant increases in total peripheral resistance and pulmonary vascular resistance are shown in Table III.

In the control series of apnoeic oxygenation,
High Frequency Jet Ventilation

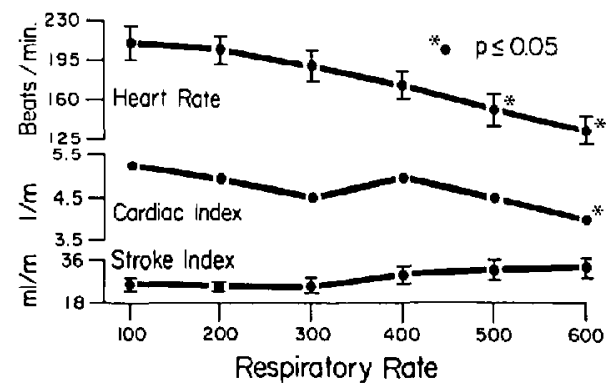

FIGURE 5 Cardiac performance changes during high frequency jet ventilation.

there was a continuous increase of $\mathrm{Pa}_{\mathrm{CO}}$ (Figure 6) at the rate of $0.53-0.67 \mathrm{kPa}$ (4-5 torr) per minute. After high frequency jet ventilation was started, the $\mathrm{Pa}_{\mathrm{CO}_{2}}$ started to decrease immediatcly and levelled off at each rate to a stable plateau, indicating the steady state for each respiratory rate. 


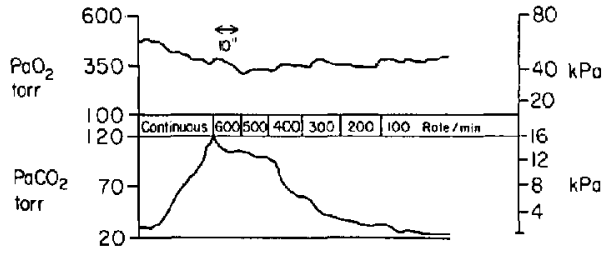

FIGURE 6 Continuous recording of arterial blood gases during apnoeic oxygenation and high frequency ventilation.

\section{Discussion}

A large tidal volume is usually advocated in intermittent positive pressure breathing ${ }^{15}$ to achieve sufficient lung expansion and gas exchange. To avoid high inspiratory peak pressures and excessive decrease of $\mathrm{Pa}_{\mathrm{CO}_{2}}$, a slow respiratory rate is then needed. This type of ventilation is frequently accompanied by a decrease of cardiac output, usually considered to be due to decreased venous return from increased intrathoracic pressure. The work of Sjostrand and collaborators ${ }^{3.4}$ showed that, by increasing the respiratory rate to 100 per minute, the depressing effect of intermittent positive pressure ventilation on the circulation can be eliminated. Our previous work ${ }^{12}$ indicated that even at respiratory rates to 200 per minute a high $\mathrm{Pa}_{\mathrm{O}_{2}}$ and a low $\mathrm{Pa}_{\mathrm{CO}_{2}}$ could be obtained with a stable circulation and augmentation of cardiac output. Lunkenheimer demonstrated that carbon dioxide elimination can be achieved even at extreme rates up to 2,400 per minute. 5

Our present series shows normal gas exchange with no circulatory impairment at rates to 400 per minute. The reason for the decrease of pulse rate at higher rates is not clear. Lunkenheimer showed that the rate of carbon dioxide removal can be increased significantly by increase in amplitude of oscillations at higher rates. This might explain why, in our experiments, there was a carbon dioxide accumulation at ventilatory rates of 500 and 600 per minute. Another possible explanation could be the exact position of the cannula in the trachea; deviation from the midline may alter the flow characteristics. Carbon dioxide did not accumulate in some experiments even at these rates and in others the rate of accumulation was higher. This particular aspect will have to be studied further.

It would be desirable to measure the tidal volume in our experiments, but the high rates and experimental design did not allow for any stan- dard method of measurement. Therefore the minute volume was measured in bench tests, insufflating with the appropriate cannula into a Douglas bag and measuring the total gas volume collected. By these measurements, a minute volume to 17 litres was achieved up to the rate of 400 per minute.

The normal tidal volume of a dog is approximately $10 \mathrm{ml} / \mathrm{kg}$. In an $18 \mathrm{~kg} \mathrm{dog}$ this would be $180 \mathrm{ml}$. In our experiments using the calculated minute volume of 17 litres and the respiratory rate of 400 рег minute (at which the $\mathrm{Pa}_{\mathrm{CO}_{2}}$ was still normal), the tidal volume would be $42 \mathrm{ml}$. Estimating the physiological dead space in the dog as 40 per cent of the tidal volume, the derived dead space is $72 \mathrm{ml}$. The calculated tidal volume of $42 \mathrm{ml}$ would then ventilate only the dead space, with no gas exchange taking place in the alveoli. Even when intratracheal insertion reduces the dead space, the tidal volume at higher rates is still smaller than the dead space. This leads us to speculate that the turbulent air flow produced by the high frequency jets allows adequate movement of gases simultaneously in and out of the lungs with no clearly differentiated inspiratory or expiratory phase, but with movement and washout of gas molecules from the alveoli.

It can be concluded that an adequate gas cxchange in the lungs does not necessarily require intermittent reciprocating action of ventilation as it occurs during spontaneous breathing. The difference between spontaneous breathing and intermittent positive ventilation (namely, the intrathoracic pressure, the flow pattern, and the influence on circulation) clearly produces an abnormal situation during intermittent positive pressure ventilation (IPPV). Therefore, there is no need for adhering to "normal" respiratory rates if a good gas exchange can be achieved at higher rates and a stable circulation maintained.

High frequency ventilation cannot be explained by apnoeic oxygenation as data of all four groups working in the field of high frequency ventilation (Sjostrand, et al. ${ }^{1-4}$, Lunkenheimer, et al., ${ }^{5}$ Butler, et al., ${ }^{6}$ and ours $)$ show gas exchange which cannot be achieved with apnoeic oxygenation.

In conclusion, intermittent positive pressure ventilation with high frequency jets introduced into the trachea without a tracheal tube is capable of maintaining adequate gas exchange in dogs at respiratory rates to 400 per minute at very low tidal volumes and low intratracheal pressures. The combination of a low tidal volume and an upper airway open to air resulted in low intra- 
tracheal pressures. There is no adverse effect on the circulation to 400 per minute. At rates of 500 and 600 per minute the heart contractility does not change, but a decreased heart rate with increased peripheral resistance produces a drop in cardiac output. There is no interference with the resumption of spontaneous ventilation during weaning.

\section{REFERENCES}

I. Jonzon, A., Oberg. P.A., Sedin. G. \& SjosTRAND, U. High frequency low tidal volume positive pressure ventilation. Acta Physiol. Scand. 80: $21 \mathrm{~A}(1970)$.

2. Jonzon, A., Orerg, P.A., Sfoin, G. \& SuosTRAND, $U$. High frequency positive pressure ventilation by endotracheal insufflation. Acta Anaesth. Scand. (Suppl. 43) (1971).

3. Hejman, K., Hejman, L., Jonzon, A., Sedin, G., SJostrand. U. \& Widman, B. High frequency positive pressure ventilation during anesthesia and routine surgery in man. Acta Anaesth. Scand. 16: 176-187(1972)

4. Jonzon, A., Sedin, G. \& Suostrand, U. Highfrequency positive pressure ventilation (HFPPV) applied for small lung ventilation and compared with spontaneous respiration and continuous positive airway pressure (CPAP). Acta Anaesth. Scand. (Suppl. 53) 23 (1973).

5. Lunkenheimer, P.P.. Rafflenteul, W., KelLe.R, H., Frank, I., Dickhut, H.H. \& FUHRMANN, C. Application of transtracheal pressure oscillations as a modification of "diffusion respiration." Br. J. Anaesth. 44: 627 (1972).
6. Butler, W.J., Bohn, D.J., Miyasaka, K. Bryan, A.C. \& Froese, A.B. Ventilation of humans by high frequency oscillation. Anesthesiology S368: 51 (1979)

7. SMITH, R.B. Transtracheal ventilation during anesthesia. Anesth. \& Analg. 53: 225-228 (1974).

8. Smith, R.B., Meyers, E.N. \& Sherman, h Transtracheal ventilation in paediatric patients case reports. Br. J. Anaesth. 46: 313-314 (1974).

9. Rock, J.J., Pfaeffle, H., Smith, R.B. Medelow, H. \& KLAIN, M. High pressure jet insufflation used to prevent aspiration and its effects on the tracheal mucosal wall. Crit. Care Med. 4: $135(1976)$

10. Smith, R.B., Babinski, M., Klain, M. \& PfaefFLE, H. Percutaneous transtracheal ventilation. J.A.C.E.P. 5: 765-770(1976).

11. Klain, M. \& SMith, R.B. Fluidic technology. Anaesthesia 31: 750-757 (1976).

12. Klain, M. \& SMITH, R.B. High frequency percutaneous transtracheal jet ventilation. Crit. Care Med. 5: 280-287 (1977)

13. Babinski, M., Klain, M. \& SMith, R.B. High frequency jet ventilation. Abstracts of Papers Presented (pp. 781-782). American Society of Anesthesiologists Annual Meeting, New Orleans, LA, October IS-19 (1977).

14. Carlon, G.C., Ray, C., Kahn, R.C. \& HowLAND. W.S. High frequency positive pressure ventilation for prolonged respiratury support. Anesthesiology S189: 51 (1979).

15. Bendixen, H.H., Hedley-Whyte, J. \& LAVER, M.B. Impaired oxygenation in surgical patients general anesthesia with controlled ventilation. New Eng. J. Med. 269: 991-996 (1963).

\section{RÉSUMÉ}

Cette étude a été entreprise dans le but de déterminer les limitations aux échanges du gaz carbonique survenant lors de la ventilation à haute fréquence réalisée par un ventilateur fluidique à jet d'oxygène et à contrôle logique. Quinze chiens ont été ventilés par cathéter transtrachéal à des fréquences allant jusqu'à 600 à la minute. Les paramètres qui suivent ont été enregistrés: la pression aortique, artérielle pulmonaire, capillaire bloquée et veineuse centrale; la pression intra-trachéale; l'électrocardiogramme; la durée des phases inspiratoire et expiratoire de l'injecteur; les tensions des gaz artériels et veineux; le débit cardiaque.

On a trouvé que les échanges gazeux restaient normaux jusqu'ả la fréquence de 400 à la minute avec des petits volumes courants et de basses pressions intratrachéales et qu'à ces fréquences, il n'y avait pas de perturbations circulatoires. La contractilité cardiaque n'a pas été affectée par des fréquences de 500 et 600 à la minute, mais une diminution de la fréquence cardiaque associée à une augmentation de la rêsistance périphérique a été à l'origine d'une baisse du débit cardiaque. Le retour à la respiration spontanée n'a pas été entravé pendant le sevrage.

Dans une série-contrôle de cinq chiens, on a eu recours à l'oxygénation apnéique et on a laissé la $\mathrm{Pa}_{\mathrm{Cu}}$ atteindre 120 torr $(15.96 \mathrm{kPa})$. On a alors débuté la ventilation à haute fréquence par injecteur à la fréquence de 600 à la minute en ralentissant progressivement par paliers de 100 torr $(13.3 \mathrm{kPa})$. Les gaz artériels ont été constamment analysés par sonde artérielle branchée sur un spectomètre de masse. La $\mathrm{Pa}_{\mathrm{CO}_{2}}$ s'est abaissée progressivement jusqu'à la normale parellèmenent à la diminution de la fréquence. 